\title{
Fruit and vegetable consumption and risk of colorectal cancer in Japan: The Miyagi Cohort Study
}

\author{
Yuki Sato ${ }^{1, *}$, Yoshitaka Tsubono ${ }^{1}$, Naoki Nakaya ${ }^{1}, K_{\text {Keiko Ogawa }}{ }^{\text {, Kayoko Kurashima }}$ ', \\ Shinichi Kuriyama', Atsushi Hozawa', Yoshikazu Nishino', Daisuke Shibuya ${ }^{2}$ and \\ Ichiro Tsuji ${ }^{1}$ \\ 'Division of Epidemiology, Department of Public Health and Forensic Medicine, Tohoku University Graduate School \\ of Medicine, 2-1 Seiryo, Aoba, Sendai 980-8575, Japan: ${ }^{2}$ Miyagi Cancer Society, Sendai, Japan
}

Submitted 27 May 2004: Accepted 28 September 2004

\begin{abstract}
Objective: Adequate fruit and vegetable intake has been suggested to protect against colorectal cancer. However, several recent prospective studies have reported no association. We therefore examined the association between fruit and vegetable intakes and the risk of colorectal cancer in a prospective cohort study in Japan.

Design: Between June and August 1990, 47605 Japanese men and women completed a self-administered questionnaire, including a food-frequency questionnaire. We divided the subjects into quartiles based on their self-reported fruit and vegetable consumption. There were 165 colon cancer and 110 rectal cancer incidences identified during 7 years of follow-up, to the end of December 1997. We used Cox proportional hazards models to estimate the relative risk (RR) of developing colorectal cancer according to the level of fruit and vegetable consumption, applying adjustments for potential confounders.

Results: No statistically significant association was observed between fruit and vegetable consumption and the risk of colorectal cancer. The multivariate RR of colon cancer in the highest quartile of fruit and vegetable intake compared with the lowest was 1.13 (95\% confidence interval (CI) $0.73-1.75$ ), the RR for vegetables alone was 1.24 (95\% CI $0.79-1.95)$ and that for fruit alone was 1.45 (95\% CI $0.85-2.47)$. The corresponding multivariate RRs for rectal cancer were 1.12 (95\% CI 0.67-1.89), 1.14 (95\% CI 0.67-1.93) and 1.41 (95\% CI 0.73-2.73).

Conclusions: We found no association between the consumption of fruit and vegetables and the risk of colorectal cancer among the Japanese population.
\end{abstract}

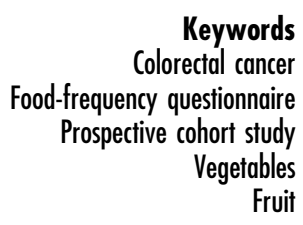

Keywords

西
ort study

Fruit
Colorectal cancer is a major cause of death in Western countries $^{1}$ and is also associated with high levels of mortality in Japan. In Japan, mortality from colorectal cancer increased rapidly between 1950 and $2001^{2}$. During this period, the age-adjusted mortality rate per 100000 for colon cancer increased 4.9-fold in men (2.9 in 1950 vs. 14.2 in 2001) and 2.9-fold in women (3.3 in 1950 vs. 9.5 in 2001). The rate for rectal cancer increased 1.6-fold in men ( 5.6 in 1950 vs. 9.2 in 2001), but remained stable in women ( 4.2 in 1950, compared with 4.1 in 2001).

A comprehensive review by the World Cancer Research Fund in 1997 examined the association between diet and colorectal cancer ${ }^{3}$. Based on 22 case-control ${ }^{4-25}$ and four prospective cohort ${ }^{26-29}$ studies, this organisation concluded that there was 'convincing' evidence to indicate that diets rich in vegetables had a protective effect against colon and rectal cancers. The data on fruit were limited and inconsistent, and no judgement was possible. However, all recent prospective cohort studies ${ }^{30-34}$ except one $\mathrm{e}^{35}$ have found no inverse association between fruit and vegetable intakes and the risk of colorectal cancer. Thus, evidence that vegetables and fruits may reduce the risk of colorectal cancer has not been established ${ }^{36}$.

The objective of our study was to prospectively examine the association between fruit and vegetable intake and the risk of colorectal cancer in Japan, where dietary habits and genetic backgrounds differ considerably from those in previous cohort studies in Western countries. To our knowledge, no previous prospective cohort study has examined this association in any Asian country, including Japan.

\section{Subjects and methods}

\section{Study cobort}

The design of the present cohort study has been described in detail elsewhere ${ }^{37}$. Briefly, between June and August 1990, we delivered a self-administered questionnaire 
on various health habits to 51921 subjects (25279 men and 26642 women) aged 40-64 years living in 14 municipalities of Miyagi Prefecture in rural northern Japan. Usable questionnaires were returned by 47605 subjects (22836 men and 24769 women), yielding 91.7\% response rate.

The study protocol was approved by the institutional review board of Tohoku University Graduate School of Medicine, and we considered return of a signed selfadministered questionnaire to imply each subject's consent to participate in the study.

\section{Dietary assessment}

Dietary intake was assessed using a self-administered 40-item food-frequency questionnaire (FFQ) asking about the average frequency of consumption of several foods. For seasonal foods, the subjects were asked to report the intake frequency in high season. Five frequency categories were used for the majority of food items (almost never, 1-2 days per month, 1-2 days per week, 3-4 days per week, almost every day). We determined a portion size for each food item based on the median values observed in 12-day dietary records (DRs) collected from separate male and female sub-samples of the subjects. We calculated the weight of total vegetables consumed each day based on six items (green leafy vegetables, carrots and pumpkins, tomatoes, cabbage and lettuce, Chinese cabbage and tsukemono (pickles)). Similarly, total fruit intake was based on three items (oranges, other fruits and fresh fruit juices). The validity of fruit and vegetable intake was assessed by calculating Spearman correlation coefficients between the DRs and the FFQ for the relevant factors. Adjusted and deattenuated Spearman correlation coefficients were 0.59 for total fruit and vegetable intake, 0.50 for total vegetable intake and 0.59 for total fruit intake. In addition, adjusted Spearman correlation coefficients between two FFQs administered 1 year apart (which acted as a measure of reproducibility) were 0.67 for total fruit and vegetables, 0.55 for total vegetables and 0.72 for total fruit intake ${ }^{38}$.

\section{Follow-up}

We identified incident cases of colon and rectal cancers that occurred in our study cohort from 1 June 1990 to 31 December 1997 by linkage of computerised records with the Miyagi Prefectural Cancer Registry, which covers the study area. We counted person-years of follow-up for each subject from 1 June 1990 until the date of diagnosis of colon or rectal cancer, the date of death, the date of moving out of the study area, or the end of the follow-up period (31 December 1997), whichever occurred first. The total numbers of person-years of follow-up accrued for the colon and rectal cancer analyses were 307779 and 307675 , respectively.

Of the 47605 subjects who responded to the questionnaire, we excluded subjects with a previous diagnosis of cancer ( $n=1110)$ and those who had extreme levels of energy intake (below or above 5\% of the range for all subjects; $n=4660$ ). Consequently, 41835 subjects (20 174 men and 21661 women) with 165 colon cancers and 110 rectal cancers were included in the present analysis.

\section{Statistical analysis}

We carried out separate analyses for colon and rectal cancers. Consumption of total vegetables and of total fruit was grouped into quartiles. Energy adjustment of food intakes was performed using the residual method ${ }^{39}$. We used Cox proportional hazards regression to calculate the relative risk (RR) and 95\% confidence interval (CI) for developing cancer, and to adjust for potentially confounding variables ${ }^{40}$. These analyses were performed using the SAS PHREG procedure on SAS version 8.2 statistical software (SAS Institute, Cary, NC, USA). The multivariate analyses were adjusted for sex, age (in years), smoking status (never, past, currently smoking 1-19 cigarettes daily, currently smoking 20 or more cigarettes daily), alcohol consumption (never, past, currently drinking $22.7 \mathrm{~g}$ or less alcohol daily, currently drinking $22.8 \mathrm{~g}$ or more alcohol daily), body mass index in $\mathrm{kg} \mathrm{m}^{-2}$ (18.4 or lower, 18.5-24.9, 25.0 or higher), education (up to 15 years of age, from 16 to 18 years, beyond the age of 19 years), family history of cancer (present, absent), time spent walking (less than $1 \mathrm{~h}$ daily, $1 \mathrm{~h}$ or longer daily) and meat consumption ( $45 \mathrm{~g}$ or less, 46-52 g, 53-62 g, $63 \mathrm{~g}$ or more daily). We repeated all analyses after excluding all subjects with colon and rectal cancer ( 45 with colon and 35 with rectal cancer) diagnosed within the first three years of follow-up, to eliminate the possibility that undiagnosed colorectal cancer that was present at baseline might influence the results for fruit and vegetable consumption. $P$-values to test for linear trends were estimated using the number of grams of fruit and vegetables consumed per day as a continuous variable. All $P$-values were two-tailed.

\section{Results}

Table 1 shows the characteristics of the subjects stratified by total fruit and vegetable consumption quartiles. No appreciable differences in median age were observed. Compared with those in the lowest quartile, the men in the highest quartile were more likely never to have smoked, to consume less alcohol, spend more time walking, have been educated to a high level and to consume more meat. We observed similar tendencies for women. Similar results were obtained when subject characteristics were analysed with respect to total vegetable and total fruit intakes (data not shown).

Table 2 presents the relative risk for colon cancer according to quartiles of total fruit and vegetable, total vegetable and total fruit consumptions. After adjustment for age and sex, consumption of total fruit and vegetables, total vegetables and total fruit showed no association with the risk of colon cancer. The age- and sex-adjusted RRs for 
Table 1 Characteristics of subjects according to consumption of total fruit and vegetables in men and women

\begin{tabular}{|c|c|c|c|c|}
\hline \multirow[b]{2}{*}{ Characteristic } & \multicolumn{4}{|c|}{ Quartile } \\
\hline & 1 (lowest) & 2 & 3 & 4 (highest) \\
\hline Energy-adjusted consumption (g) & $\leq 543$ & $544-616$ & $617-697$ & $\geq 698$ \\
\hline \multicolumn{5}{|l|}{ Men } \\
\hline Number of subjects & 5130 & 5342 & 4786 & 4916 \\
\hline Age (years), mean $\pm S D$ & $52.0 \pm 7.6$ & $51.1 \pm 7.6$ & $51.5 \pm 7.7$ & $52.2 \pm 7.6$ \\
\hline Current smoker (\%) & 65.3 & 62.3 & 57.3 & 54.4 \\
\hline Current drinker (\%) & 80.1 & 77.9 & 75.9 & 70.0 \\
\hline Body mass index $\geq 25.0 \mathrm{~kg} \mathrm{~m}^{-2}$ (\%) & 25.3 & 26.9 & 25.0 & 26.6 \\
\hline Walking time $<1$ h day $^{-1}(\%)$ & 47.4 & 54.8 & 52.2 & 50.3 \\
\hline Family history of cancer in first-degree relative (\%) & 24.2 & 24.2 & 26.0 & 27.2 \\
\hline Education, in school until age 19 years or older (\%) & 8.0 & 13.5 & 15.0 & 16.6 \\
\hline Meat consumption per day $\geq 63 \mathrm{~g}(\%)$ & 14.1 & 24.8 & 30.9 & 35.6 \\
\hline \multicolumn{5}{|l|}{ Women } \\
\hline Number of subjects & 5332 & 5227 & 5619 & 5483 \\
\hline Age (years), mean $\pm S D$ & $52.1 \pm 7.5$ & $52.1 \pm 7.5$ & $51.9 \pm 7.4$ & $52.5 \pm 7.4$ \\
\hline Current smoker (\%) & 8.3 & 6.7 & 5.7 & 5.9 \\
\hline Current drinker (\%) & 21.2 & 21.5 & 20.7 & 19.6 \\
\hline Body mass index $\geq 25.0 \mathrm{~kg} \mathrm{~m}^{-2}(\%)$ & 29.6 & 30.1 & 29.8 & 30.4 \\
\hline Walking time $<1 \mathrm{~h}$ day $^{-1}(\%)$ & 43.7 & 51.0 & 52.3 & 50.5 \\
\hline Family history of cancer in first-degree relative (\%) & 25.0 & 28.1 & 29.0 & 29.1 \\
\hline Education, in school until age 19 years or older (\%) & 7.9 & 11.0 & 13.7 & 14.3 \\
\hline Meat consumption per day $\geq 63 \mathrm{~g}(\%)$ & 15.8 & 22.9 & 25.8 & 24.8 \\
\hline
\end{tabular}

SD - standard deviation.

Total fruit and vegetables consist of the following: orange, other fruits and fresh fruit juices, green leaf vegetables, carrots and pumpkins, tomatoes, cabbage and lettuce, Chinese cabbage and tsukemono (pickles).

Table 2 Relative risk (RR) (95\% confidence interval) of colon cancer for fruit and vegetables consumption

\begin{tabular}{|c|c|c|c|c|c|}
\hline \multirow[b]{2}{*}{ Food group and variable } & \multicolumn{4}{|c|}{ Quartile } & \multirow[b]{2}{*}{$P$-value for trend } \\
\hline & 1 (lowest) $^{*}$ & 2 & 3 & 4 (highest) & \\
\hline \multicolumn{6}{|l|}{ Total fruit and vegetables } \\
\hline Energy-adjusted consumption (g) & $\leq 543$ & $544-616$ & $617-697$ & $\geq 698$ & \\
\hline Number of cases & 41 & 39 & 35 & 50 & \\
\hline Person-years of follow-up & 76960 & 77650 & 76570 & 76495 & \\
\hline Age- and sex-adjusted RR & 1.00 & $1.00(0.65-1.56)$ & $0.93(0.59-1.47)$ & $1.24(0.82-1.88)$ & 0.36 \\
\hline Multivariate RR1 & 1.00 & $0.92(0.59-1.45)$ & $0.83(0.52-1.32)$ & $1.13(0.73-1.75)$ & 0.62 \\
\hline Multivariate RR2 & 1.00 & $0.86(0.51-1.45)$ & $0.74(0.43-1.28)$ & $1.05(0.64-1.75)$ & 0.90 \\
\hline \multicolumn{6}{|l|}{ Total vegetables } \\
\hline Energy-adjusted consumption (g) & $\leq 245$ & $246-277$ & $278-312$ & $\geq 313$ & \\
\hline Number of cases & 35 & 47 & 41 & 50 & \\
\hline Person-years of follow-up & 77878 & 77269 & 75271 & 77257 & \\
\hline Age- and sex-adjusted RR & 1.00 & $1.14(0.74-1.84)$ & $1.25(0.79-1.95)$ & $1.34(0.87-2.07)$ & 0.17 \\
\hline Multivariate RR1 & 1.00 & $1.10(0.69-1.75)$ & $1.13(0.71-1.80)$ & $1.24(0.79-1.95)$ & 0.34 \\
\hline Multivariate RR2 & 1.00 & $1.11(0.65-1.88)$ & $0.98(0.57-1.70)$ & $1.18(0.70-1.98)$ & 0.64 \\
\hline \multicolumn{6}{|l|}{ Total fruit } \\
\hline Energy-adjusted consumption (g) & $\leq 95$ & $96-169$ & $170-241$ & $\geq 242$ & \\
\hline Number of cases & 47 & 47 & 35 & 36 & \\
\hline Person-years of follow-up & 76617 & 76809 & 77868 & 76380 & \\
\hline Age- and sex-adjusted RR & 1.00 & $1.33(0.88-2.01)$ & $1.18(0.74-1.90)$ & $1.52(0.91-2.52)$ & 0.17 \\
\hline Multivariate RR1 & 1.00 & $1.30(0.85-1.98)$ & $1.16(0.71-1.89)$ & $1.45(0.85-2.47)$ & 0.28 \\
\hline Multivariate RR2 & 1.00 & $1.55(0.94-2.54)$ & $1.41(0.80-2.48)$ & $1.43(0.75-2.72)$ & 0.31 \\
\hline
\end{tabular}

RR1 - multivariate relative risk with all cases of colon cancer in analysis; RR2 - multivariate relative risk with cases diagnosed in the first three years of follow-up excluded from analysis.

Total fruit and vegetables consist of the following: orange, other fruits and fresh fruit juices, green leaf vegetables, carrots and pumpkins, tomatoes, cabbage and lettuce, Chinese cabbage and tsukemono (pickles).

Total vegetables consist of the following: green leaf vegetables, carrots and pumpkins, tomatoes, cabbage and lettuce, Chinese cabbage and tsukemono (pickles).

Total fruit consist of the following: orange, other fruits and fresh fruit juices.

Multivariate models included: sex; age (in years); smoking status (never, past, currently smoking 1-19 cigarettes daily, currently smoking over 20 cigarettes daily); alcohol consumption (never, past, currently drinking $22.7 \mathrm{~g}$ or less alcohol daily, currently drinking $22.8 \mathrm{~g}$ or more alcohol daily); body mass index in $\mathrm{kg} \mathrm{m}^{-2}$ (18.4 or lower, 18.5-24.9, 25.0 or higher); education (up to 15 years of age, from 16 to 18 years, 19 years or older); family history of cancer (present, absent); walking time (less than $1 \mathrm{~h}$ daily, over $1 \mathrm{~h}$ daily); meat consumption (in quartiles $-45 \mathrm{~g}$ or less, $46-52 \mathrm{~g}, 53-62 \mathrm{~g}$ or $63 \mathrm{~g}$ or more daily).

${ }^{*}$ Referent category. 
the highest versus the lowest quartiles for consumption of total fruit and vegetables, total vegetables and total fruit were 1.24 (95\% CI 0.82-1.88; $P$-trend $=0.36), 1.34(95 \%$ CI $0.87-2.07 ; P$-trend $=0.17)$ and $1.52(95 \%$ CI $0.91-2.52$; $P$-trend $=0.17)$, respectively. Neither multivariate adjustments nor the exclusion of subjects with colon cancer diagnosed during the first three years of follow-up made any material changes to the findings.

We observed no associations between total fruit and vegetables, total vegetables and total fruit intakes and the risk of colon cancer when men and women were analysed separately. Specifically, the multivariate RRs for men in the highest versus the lowest quartiles for consumption of total fruit and vegetables, total vegetables and total fruit were $0.92(95 \%$ CI $0.54-1.59 ; P$-trend $=0.84), 1.00(95 \%$ CI $0.56-1.77 ; P$-trend $=0.91)$ and 1.75 (95\% CI 0.89-3.44; $P$-trend $=0.23)$, respectively. Corresponding RRs for women were $1.55(95 \%$ CI $0.72-3.32 ; P$-trend $=0.36)$, 1.65 (95\% CI 0.78-3.49; $P$-trend $=0.13)$ and $0.99(95 \% \mathrm{CI}$ $0.23-4.25 ; P$-trend $=0.79)$.

Table 3 presents the relative risks for rectal cancer according to the total fruit and vegetables, total vegetables and total fruit consumption quartiles. After adjustment for age and sex, consumption of total fruit and vegetables, total vegetables and total fruit showed no association with the risk of rectal cancer. The age- and sex-adjusted RRs for the highest versus the lowest quartiles for consumption of total fruit and vegetables, total vegetables and total fruit were $1.12(95 \%$ CI $0.68-1.84 ; P$-trend $=0.40), 1.17(95 \%$ CI 0.70-1.94; $P$-trend $=0.49)$ and 1.33 (95\% CI 0.71-2.51; $P$-trend $=0.37)$, respectively. Again, neither multivariate adjustments nor the exclusion of subjects with rectal cancer diagnosed during the first three years of follow-up had any substantial impact on the findings.

As with colon cancer, we observed no association between total fruit and vegetables, total vegetables and total fruit consumption and the risk of rectal cancer when men and women were analysed separately. Specifically, multivariate RRs for men in the highest versus the lowest quartile for consumption of total fruit and vegetables, total vegetables and total fruit were 1.10 (95\% CI 0.55-2.17; $P$-trend $=0.51), 1.32(95 \%$ CI $0.67-2.60 ; P$-trend $=0.23)$ and 0.28 (95\% CI 0.04-2.09; $P$-trend $=0.75)$, respectively. Corresponding RRs for women were 1.26 (95\% CI $0.56-2.86 ; P$-trend $=0.42), 0.99(95 \%$ CI $0.42-2.32 ; P$ trend $=0.73$ ). For total fruit consumption, there were no cases of rectal cancer in the reference category (the lowest quartile), so we conducted the analysis with reference to the lowest and second lower quartiles combined. The RR was 1.53 (95\% CI $0.68-3.45 ; P$-trend $=0.23)$.

Table 3 Relative risk (RR) (95\% confidence interval) of rectal cancer for fruit and vegetables consumption

\begin{tabular}{|c|c|c|c|c|c|}
\hline \multirow[b]{2}{*}{ Food group and variable } & \multicolumn{4}{|c|}{ Quartile } & \multirow[b]{2}{*}{$P$-value for trend } \\
\hline & 1 (lowest)* $^{\star}$ & 2 & 3 & 4 (highest) & \\
\hline \multicolumn{6}{|l|}{ Total fruit and vegetables } \\
\hline Energy-adjusted consumption (g) & $\leq 543$ & $544-616$ & $617-697$ & $\geq 698$ & \\
\hline Number of cases & 30 & 19 & 28 & 33 & \\
\hline Person-years of follow-up & 76987 & 77687 & 76581 & 76524 & \\
\hline Age- and sex-adjusted RR & 1.00 & $0.66(0.37-1.17)$ & $1.00(0.60-1.67)$ & $1.12(0.68-1.84)$ & 0.40 \\
\hline Multivariate RR1 & 1.00 & $0.62(0.35-1.12)$ & $0.97(0.57-1.65)$ & $1.12(0.67-1.89)$ & 0.37 \\
\hline Multivariate RR2 & 1.00 & $0.57(0.28-1.16)$ & $1.00(0.53-1.88)$ & $1.08(0.58-2.03)$ & 0.47 \\
\hline \multicolumn{6}{|l|}{ Total vegetables } \\
\hline Energy-adjusted consumption (g) & $\leq 245$ & $246-277$ & $278-312$ & $\geq 313$ & \\
\hline Number of cases & 27 & 26 & 26 & 33 & \\
\hline Person-years of follow-up & 77885 & 77302 & 75302 & 77289 & \\
\hline Age- and sex-adjusted RR & 1.00 & $0.92(0.53-1.60)$ & $1.02(0.59-1.75)$ & $1.17(0.70-1.94)$ & 0.49 \\
\hline Multivariate RR1 & 1.00 & $0.87(0.50-1.52)$ & $0.96(0.55-1.66)$ & $1.14(0.67-1.93)$ & 0.55 \\
\hline Multivariate RR2 & 1.00 & $1.05(0.54-2.07)$ & $1.13(0.58-2.20)$ & $1.18(0.61-2.28)$ & 0.61 \\
\hline \multicolumn{6}{|l|}{ Total fruit } \\
\hline Energy-adjusted consumption (g) & $\leq 95$ & $96-169$ & $170-241$ & $\geq 242$ & \\
\hline Number of cases & 30 & 29 & 27 & 24 & \\
\hline Person-years of follow-up & 76662 & 76854 & 77861 & 76402 & \\
\hline Age- and sex-adjusted RR & 1.00 & $1.20(0.71-2.03)$ & $1.27(0.72-2.26)$ & $1.33(0.71-2.51)$ & 0.37 \\
\hline Multivariate RR1 & 1.00 & $1.26(0.74-2.15)$ & $1.36(0.75-2.47)$ & $1.41(0.73-2.73)$ & 0.30 \\
\hline Multivariate RR2 & 1.00 & $1.21(0.63-2.30)$ & $1.17(0.56-2.44)$ & $1.33(0.60-2.86)$ & 0.52 \\
\hline
\end{tabular}

RR1 - multivariate relative risk with all cases of colon cancer in analysis; RR2 - multivariate relative risk with cases diagnosed in the first three years of follow-up excluded from analysis.

Total fruit and vegetables consist of the following: orange, other fruits and fresh fruit juices, green leaf vegetables, carrots and pumpkins, tomatoes, cabbage and lettuce, Chinese cabbage and tsukemono (pickles).

Total vegetables consist of the following: green leaf vegetables, carrots and pumpkins, tomatoes, cabbage and lettuce, Chinese cabbage and tsukemono (pickles).

Total fruit consist of the following: orange, other fruits and fresh fruit juices.

Multivariate models included: sex; age (in years); smoking status (never, past, currently smoking 1-19 cigarettes daily, currently smoking over 20 cigarettes daily); alcohol consumption (never, past, currently drinking $22.7 \mathrm{~g}$ or less alcohol daily, currently drinking $22.8 \mathrm{~g}$ or more alcohol daily); body mass index in $\mathrm{kg} \mathrm{m}^{-2}$ (18.4 or lower, 18.5-24.9, 25.0 or higher); education (up to 15 years of age, from 16 to 18 years, 19 years or older); family history of cancer (present, absent); walking time (less than $1 \mathrm{~h}$ daily, over $1 \mathrm{~h}$ daily); meat consumption (in quartiles $-45 \mathrm{~g}$ or less, $46-52 \mathrm{~g}, 53-62 \mathrm{~g}$ or $63 \mathrm{~g}$ or more daily).

${ }^{*}$ Referent category. 
We further examined associations between the consumption of six specific types of vegetable (green leafy vegetables, carrots and pumpkins, tomatoes, cabbage and lettuce, Chinese cabbage and tsukemono (pickles)) and three types of fruit (oranges, other fruits and fresh fruit juices) and the risks of colon and rectal cancer, but found no significant correlations.

\section{Discussion}

In this population-based prospective cohort study in Japan, we found no significant associations between the intake of fruit or vegetables and the risk of colon or rectal cancer. Six prospective cohort studies published over the past 5 years have investigated the association between fruit and vegetable consumption and the risk of colon and rectal cancer. Of these, only one Swedish study found an inverse correlation ${ }^{35}$; the remaining five reported no association $^{30-34}$. Our results are consistent with those of the latter five studies.

There are several possible interpretations of our finding that fruit and vegetable intake had no protective effect against colorectal cancer. First, the range of fruit and vegetable consumption among the subjects may not have been wide enough to produce positive effects. Among our study subjects, there was only a 1.5 -fold difference across the total fruit and vegetables consumption quartiles (median intake was $506 \mathrm{~g}$ in the lowest and $758 \mathrm{~g}$ in the highest). Terry et al. reported an increased risk of colorectal cancer among the lowest consumers of total fruit and vegetables ${ }^{35}$. In their study, there was a 3.0-fold difference across the fruit and vegetable consumption quartiles. In contrast, although their study showed a wide range of consumption (a 3.9-fold difference across the quintiles for vegetables and a 10.0-fold difference for fruit), Flood et al. reported null association between the risks of colorectal cancer and fruit and vegetable consumption $^{30}$. Thus, effect of range does not provide a full explanation for our null associations.

Second, we have to consider the effects of possible misclassification when completing the FFQ. If many FFQs containing misclassifications are used to estimate dietary consumption, the general results are likely to be distorted, and the effect of fruit and/or vegetables consumption on the risks of colorectal cancer risk might be attenuated. However, in our validation study, the Spearman correlation coefficients for fruit and vegetables consumption were relatively high, ranging from 0.50 to $0.59^{38}$. Thus, the effect of misclassification may not fully explain our null results.

In conclusion, during a population-based prospective cohort study in Japanese subjects, we found no association between the consumption of fruit and vegetables and the risks of colon and rectal cancers. These findings are in agreement with the results of several other similarly designed studies, and add to the debate regarding the suggested protective effects of fruit and vegetables against colorectal cancer.

\section{Acknowledgements}

This study was supported in part by Grants-in-Aid for Scientific Research from the Ministry of Education, Science, Sports and Culture (09470106) and by Health Sciences Research Grants for Research on Health Services (H10-25) from the Ministry of Health and Welfare in Japan.

\section{References}

1 International Agency for Research on Cancer (IARC). Cancer Incidence, Mortality and Prevalence Worldwide, Version 1.O. IARC Cancer Base No. 5. Lyon: IARC Press, 2001.

2 Statistics and Information Department, Minister's Secretariat, Ministry of Health, Labour and Welfare, Japan. Vital Statistics of Japan (1950-2001). Tokyo: Health and Welfare Statistics Association, 1952-2003 (in Japanese).

3 World Cancer Research Fund (WRCF)/American Institute for Cancer Research (AICR). Food, Nutrition and The Prevention of Cancer: A Global Perspective. Washington, DC: WCRF/AICR, 1997.

4 Kampman E, Goldbohm A, van den Brandt PA, van't Veer P. Fermented dairy products, calcium, and colorectal cancer in the Netherlands cohort study. Cancer Research 1994; 54: 3186-90.

5 Steinmetz KA, Potter JD. Food group consumption and colon cancer in the Adelaide case-control study. I. Vegetables and fruit. International Journal of Cancer 1993; 53: 711-9.

6 Iscovich JM, L'Abbee KA, Castelleto R, Calzona A, Bernedo A, Chopita NA, et al. Colon cancer in Argentina I: risk from intake of dietary items. International Journal of Cancer 1992; 51: 851-7.

7 Peters RK, Pike MC, Garabrant D, Mack TM. Diet and colon cancer in Los Angeles County, California. Cancer Causes \& Control 1992; 3: 457-73.

8 Bidoli E, Franceschi S, Talamini R, Barra S, La Vecchia C. Food consumption and cancer of the colon and rectum in north-eastern Italy. International Journal of Cancer 1992; 50: $223-9$.

9 Hu JF, Liu YY, Yu YK, Zhao TZ, Liu SD, Wang QQ. Diet and cancer of the colon and rectum: a case-control study in China. International Journal of Epidemiology 1991; 20: $362-7$.

10 Benito E, Obrador A, Stiggelbout A, Bosch FX, Mulet M, Munoz N, et al. A population-based case-control study of colorectal cancer in Majorca. I. Dietary factors. International Journal of Cancer 1990; 45: 69-76.

11 West DW, Slattery ML, Robison LM, Schuman KL, Ford MH, Mahoney AW, et al. Dietary intake and colon cancer: sexand anatomic site-specific associations. American Journal of Epidemiology 1989; 130: 883-94.

12 Lee HP, Gourley L, Duffy SW, Esteve J, Lee J, Day NE. Colorectal cancer and diet in an Asian population - a casecontrol study among Singapore Chinese. International Journal of Cancer 1989; 43: 1007-16.

13 Young TB, Wolf DA. Case-control study of proximal and distal colon cancer and diet in Wisconsin. International Journal of Cancer 1988; 42: 167-75.

14 Tuyns AJ, Kaaks R, Haelterman M. Colorectal cancer and the consumption of foods: a case-control study in Belgium. Nutrition and Cancer 1988; 11: 189-204.

15 Slattery ML, Sorenson AW, Ford MH. Dietary calcium intake as a mitigating factor in colon cancer. American Journal of Epidemiology 1988; 128: 504-14. 
16 LaVecchia C, Negri E, Decarli A, D’Avanzo B, Gallotti L, Gentile A, et al. A case-control study of diet and colo-rectal cancer in northern Italy. International Journal of Cancer 1988; 41: 492-8.

17 Graham S, Marshall J, Haughey B, Mittelman A, Swanson M, Zielezny M, et al. Dietary epidemiology of cancer of the colon in western New York. American Journal of Epidemiology 1988; 128: 490-503.

18 Kune S, Kune GM, Watson F. Case-control study of dietary etiologic factors: the Melbourne colorectal cancer study. Nutrition and Cancer 1987; 9: 21-42.

19 Macquart-Moulin G, Riboli E, Cornee J, Charnay B, Berthezene P, Day N. Case-control study on colorectal cancer and diet in Marseilles. International Journal of Cancer 1986; 38: 183-91.

20 Tajima K, Tominga S. Dietary habits and gastro-intestinal cancers: a comparative case-control study of stomach and large intestinal cancers in Nagoya Japan. Japanese Journal of Cancer Research 1985; 76: 705-16.

21 Miller AB, Howe GR, Jain M, Craib KJ, Harrison L. Food items and food groups as risk factors in a case-control study of diet and colorectal cancer. International Journal of Cancer 1983; 32: 155-61.

22 Graham S, Dayal H, Swanson M, Mittelman A, Wilkinson G. Diet in the epidemiology of cancer of the colon and rectum. Journal of the National Cancer Institute 1978; 61: 709-14.

23 Phillips R. Role of life-style and dietary habits in risk of cancer among Seventh-day Adventists. Cancer Research 1975; 35: 3513-22.

24 Modan B, Barell V, Lubin F, Modan M, Greenberg RA, Graham S. Low-fiber intake as an etiologic factor in cancer of the colon. Journal of the National Cancer Institute 1975; 55 : $15-8$.

25 Bjelke E. Epidemiologic studies of cancer of the stomach, colon, and rectum; with special emphasis on the role of diet. Scandinavian Journal of Gastroenterology. Supplement 1974; 9: 124-229.

26 Steinmetz KA, Kushi LH, Bostick RM, Folsom AR, Potter JD. Vegetables, fruit and colon cancer in the Iowa Women's Health Study. American Journal of Epidemiology 1994; 139: $1-15$.

27 Shibata A, Paganini Hill A, Ross RK, Henderson BE. Intake of vegetables, fruits, beta-carotene, vitamin $\mathrm{C}$ and vitamin supplements and cancer incidence among the elderly: a prospective study. British Journal of Cancer 1992; 66: 673-9.

28 Thun MJ, Calle EE, Namboodiri MM, Flanders WD, Coates RJ, Byers T, et al. Risk factors for fatal colon cancer in a large prospective study. Journal of the National Cancer Institute 1992; 84: 1491-500.

29 Phillips RL, Snowdon DA. Dietary relationships with fatal colorectal cancer among Seventh-Day Adventists. Journal of the National Cancer Institute 1985; 74: 307-17.

30 Flood A, Velie EM, Chaterjee N, Subar AF, Thompson FE, Lacey JV Jr, et al. Fruit and vegetable intakes and the risk of colorectal cancer in the Breast Cancer Detection Demonstration Project follow-up cohort. American Journal of Clinical Nutrition 2002; 75: 936-43.

31 Michels KB, Giovannucci E, Joshipura KJ, Rosner BA, Stampfer MJ, Fuchs CS, et al. Prospective study on fruit and vegetable consumption and incidence of colon and rectal cancers. Journal of the National Cancer Institute 2000; 92 $1740-52$.

32 Voorrips LE, Goldbohm RA, van Popeel G, Sturmans F, Hermus RJJ, van den Brandt PA. Vegetable and fruit consumption and risks of colon and rectal cancer in a prospective cohort study; The Netherlands Cohort Study on Diet and Cancer. American Journal of Epidemiology 2000; 152: $1081-92$

33 Pietinen P, Malila N, Virtanen M, Hartman TJ, Tangrea JA, Albanes D, et al. Diet and risk of colorectal cancer in a cohort of Finnish men. Cancer Causes \& Control 1999; 10: 387-96.

34 Singh PN, Fraser GE. Dietary risk factors for colon cancer in a low-risk population. American Journal of Epidemiology 1998; 148: 761-74

35 Terry P, Giovannucci E, Michels KB, Bergkvist L, Hansen H, Holmberg L, et al. Fruit, vegetables, dietary fiber and risk of colorectal cancer. Journal of the National Cancer Institute 2001; 93: 525-33.

36 Key TJ, Schatzkin A, Willett WC, Allen NE, Spencer EA, Travis RC. Diet, nutrition and the prevention of cancer. Public Health Nutrition 2004; 7: 187-200.

37 Fukao A, Tsubono Y, Komatsu S, Tsuji I, Minami Y, Hisamichi S, et al. A cohort study on the relation of lifestyle, personality and biologic markers to cancer in Miyagi, Japan: study design, response rate and profiles of the cohort subjects. Journal of Epidemiology 1995; 5: 153-7.

38 Ogawa K, Tsubono Y, Nishino Y, Watanabe Y, Ohkubo T, Watanabe $\mathrm{T}$, et al. Validation of a food-frequency questionnaire for cohort studies in rural Japan. Public Health Nutrition 2003; 6: 147-57.

39 Willett WC, Stampfer MJ. Total energy intake: implications for epidemiologic analyses. American Journal of Epidemiology 1986; 124: 17-27.

40 Rothman KJ, Greenland S. Modern Epidemiology, 2nd ed. Philadelphia, PA: Lippincott-Raven, 1998. 